\section{Prospective study of risk factors for attempted suicide among patients with DSM-IV major}

\section{depressive disorder}

\author{
T. PETTERI SOKERO, TARJA K. MELARTIN, HEIKKI J. RYTSÄLÄ, \\ ULLA S. LESKELÄ, PAULA S. LESTELÄ-MIELONEN \\ and ERKKI T. ISOMETSÄ
}

\author{
Background There are few \\ prospective studies on risk factors for \\ attempted suicide among psychiatric \\ out- and in-patients with major depressive \\ disorder.
}

\begin{abstract}
Aims To investigate risk factors for attempted suicide among psychiatric out- and in-patients with major depressive disorder in the city of Vantaa, Finland.
\end{abstract}

\begin{abstract}
Method The Vantaa Depression Study included 269 patients with DSM-IV major depressive disorder diagnosed using semistructured interviews and followed up at 6 - and 18 -month interviews with a life chart.
\end{abstract}

Results During the 18-month followup, $8 \%$ of the patients attempted suicide. The relative risk of an attempt was 2.50 during partial remission and 7.54 during a major depressive episode, compared with full remission $(P<0.001)$. Numerous factors were associated with this risk, but lacking a partner, previous suicide attempts and total time spent in major depressive episodes were the most robust predictors.

\section{Conclusions Suicide attempts among patients with major depressive disorder are strongly associated with the presence and severity of depressive symptoms and predicted by lack of partner, previous suicide attempts and time spent in depression. Reducing the time spent depressed is a credible preventive measure.}

Declaration of interest None.
Major depressive disorder among inpatients carries about a 20-fold risk of completed suicide (Osby et al, 2001) and about half of people who complete suicide have attempted suicide at least once before (Isometsä et al, 1994). The lifetime risk of a non-fatal suicide attempt among patients with major depressive disorder is estimated at about $40 \%$ (Malone et al, 1995), and may be an important proxy outcome when investigating risk factors for suicide. In the few published prospective studies, risk factors for suicide attempt (Paykel \& Dienelt, 1971; Duggan et al, 1991; Bronisch \& Hecht, 1992; Oquendo et al, 2002) or completed suicide (Fawcett et al, 1990; Nordström et al 1995; Hansen et al, 2003) have included a history of suicide attempt by the patient or suicide in the family (Paykel \& Dienelt, 1971; Fawcett et al, 1990; Bronisch \& Hecht, 1992; Nordström et al, 1995), high severity of depression (Oquendo et al, 2002; Hansen et al, 2003), comorbid personality disorder (Paykel \& Dienelt, 1971; Hansen et al, 2003), comorbid alcohol dependence or misuse (Fawcett et al, 1990; Duggan et al, 1991; Bronisch \& Hecht, 1992), comorbid chronic physical illness (Duggan et al, 1991), younger age (Paykel \& Dienelt, 1971), hopelessness and suicidal ideation (Fawcett et al, 1990). However, most of these prospective studies have been conducted exclusively within in-patient settings (Duggan et al, 1991; Bronisch \& Hecht, 1992; Nordström et al, 1995; Oquendo et al, 2002; Hansen et al, 2003), have had relatively small $(n<100)$ sample sizes (Duggan et al, 1991; Bronisch \& Hecht, 1992) or have investigated populations with diagnostically mixed affective disorders (Fawcett et al, 1990; Nordström et al, 1995). Therefore the generalisability of their findings to other settings or populations, or their power to detect risk factors, may have been limited. Previously we have reported factors cross-sectionally associated with suicidal ideation and attempts among psychiatric patients with major depressive disorder (Sokero et al, 2003). In the present prospective study we hypothesised that presence and severity of depression, comorbid substance use, cluster B personality and anxiety disorders, and social support and history of previous suicide attempts would each independently predict suicide attempts.

\section{METHOD}

\section{Setting}

The background and methodology of the Vantaa Depression Study have been described in detail elsewhere (Melartin et $a l, 2002,2004)$. In brief, the Vantaa Depression Study is a collaborative depression research project between the Department of Mental Health and Alcohol Research of the National Public Health Institute, Helsinki, Finland, and the Department of Psychiatry of the Peijas Medical Care District, Vantaa, Finland. Vantaa is the fourth largest city in Finland, with a population of 169000 in 1997, and provides psychiatric services to all its citizens free of charge. The Vantaa Depression Study was accepted by the ethical committee of the Peijas Medical Care District in December 1996.

\section{Screening, diagnostic evaluation and baseline measurements}

In the first phase, all patients $(n=806)$ at the Department of Psychiatry of the Peijas Medical Care District were screened for a possible new episode of DSM-IV (American Psychiatric Association, 1994) major depressive disorder between 1 February 1997 and 31 May 1998 (Melartin et al, 2002). Patients with a positive screen were fully informed about the study project and their participation was requested. Of the 703 eligible patients, 542 (77\%) agreed and gave written informed consent.

In the second phase a researcher using SCAN 2.0 (Wing et al, 1990) interviewed the 542 consenting patients, 269 of whom were diagnosed with DSM-IV major depressive disorder and were included in the study; the diagnostic reliability was excellent $(\kappa=0.86,95 \%$ CI $0.58-1.0)$ (Melartin et al, 2002). The Structured Clinical Interview for DSM-III-R personality disorders (SCID-II; Spitzer et al, 1987) was used to assess diagnoses on Axis II. The cohort baseline measurements included the 17-item Hamilton Rating Scale for Depression (HRSD; Hamilton, 1960), 21-item Beck 
Table I Differences in characteristics between those who did and did not attempt suicide out of the 198 patients with unipolar major depressive disorder during the I8-month prospective follow-up

\begin{tabular}{|c|c|c|c|c|}
\hline Characteristic & No suicide attempt & Suicide attempt & All patients & $P$ \\
\hline Total, $n(\%)$ & $182(92)$ & $16(8)$ & $198(100)$ & \\
\hline \multicolumn{5}{|l|}{ Socio-demographic features } \\
\hline \multicolumn{5}{|l|}{ Gender, $n(\%)$} \\
\hline Male & $5 I(28)$ & $4(25)$ & $55(28)$ & \\
\hline Female & I3I (72) & $12(78)$ & $143(72)$ & \\
\hline Married or cohabiting, $n(\%)$ & $104(57)$ & $3(19)$ & $107(54)$ & $0.004^{\prime}$ \\
\hline Age (years), mean (s.d.) & $41.2(I 1.0)$ & $38.4(11.3)$ & $4 I .0(I I . I)$ & \\
\hline PSSS-R score, mean (s.d.) & $39.4(12.8)$ & $35.2(14.4)$ & $39.0(13.0)$ & \\
\hline \multicolumn{5}{|l|}{ Depression-related characteristics } \\
\hline Severity of depression at baseline & & & & $0.02^{2}$ \\
\hline Mild & II (6) & - & II (6) & \\
\hline Moderate & $99(54)$ & $4(25)$ & $103(52)$ & \\
\hline Severe & $72(40)$ & $12(75)$ & $84(42)$ & \\
\hline Psychotic features, $n(\%)$ & II (6) & $2(13)$ & $13(7)$ & \\
\hline Melancholic features, $n(\%)$ & $67(37)$ & $7(44)$ & $74(37)$ & \\
\hline Time to full remission (months), mean (s.d.) & $4.0(4.7)$ & $8.1(7.5)$ & $4.4(5.1)$ & $0.002^{3}$ \\
\hline Total time in depression (months), mean (s.d.) & $4.4(4.7)$ & $8.6(7.1)$ & $4.8(5.0)$ & $0.002^{4}$ \\
\hline \multicolumn{5}{|l|}{ Symptom scores } \\
\hline HRSD score, mean (s.d.) & $18.6(5.9)$ & $23.8(6.0)$ & $19.1(6.1)$ & $0.001^{5}$ \\
\hline SSI score, mean (s.d.) & $5.5(7.3)$ & $12.6(10.7)$ & $6.1(7.8)$ & $0.008^{6}$ \\
\hline BDI score, mean (s.d.) & $27.0(8.1)$ & $31.1(7.7)$ & $27.4(10.8)$ & $0.057^{7}$ \\
\hline BAl score, mean (s.d.) & $21.2(10.6)$ & $27.4(11.0)$ & $21.7(10.8)$ & $0.026^{8}$ \\
\hline BHS score, mean (s.d.) & $10.0(4.7)$ & II.4 (4.0) & $10.1(4.7)$ & \\
\hline SOFAS score, mean (s.d.) & $52.7(10.2)$ & $48.3(12.6)$ & $52.3(10.4)$ & \\
\hline \multicolumn{5}{|l|}{ History of suicidal behaviour } \\
\hline Suicide during attempt index episode, $n$ (\%) & $2 I(I I)$ & $7(44)$ & $28(14)$ & $0.003^{\prime}$ \\
\hline Suicide attempt before index episode, $n(\%)$ & $42(23)$ & $4(25)$ & $46(23)$ & \\
\hline Suicide attempt before/during index episode, $n$ (\%) & $55(30)$ & $9(56)$ & $64(32)$ & 0.0491 \\
\hline \multicolumn{5}{|l|}{ Psychiatric comorbidity } \\
\hline Psychiatric comorbidity (any), $n$ (\%) & 14I (78) & $13(81)$ & $154(78)$ & \\
\hline Alcohol dependence/misuse, $n$ (\%) & $40(22)$ & $4(25)$ & $44(22)$ & \\
\hline Alcohol dependence, $n$ (\%) & $21(12)$ & $2(13)$ & $23(12)$ & \\
\hline Alcohol misuse, $n$ (\%) & $19(10)$ & $2(13)$ & $2 I(I I)$ & \\
\hline Personality disorder (any), $n$ (\%) & $74(4 I)$ & II (69) & $85(43)$ & $0.036^{1}$ \\
\hline Cluster A & $32(18)$ & $5(31)$ & $37(19)$ & \\
\hline Cluster B & $24(13)$ & $4(25)$ & $28(14)$ & \\
\hline Cluster C & $54(30)$ & $8(50)$ & $62(31)$ & \\
\hline BPD & $20(I I)$ & $3(20)$ & $23(12)$ & \\
\hline Anxiety disorder (any), $n$ (\%) & $98(54)$ & $10(63)$ & $108(54)$ & \\
\hline Panic disorder & $22(12)$ & $4(25)$ & $26(13)$ & \\
\hline Agoraphobia without panic & $20(\mathrm{II})$ & $2(13)$ & $22(\mathrm{II})$ & \\
\hline Social phobia & $30(17)$ & $4(25)$ & $34(17)$ & \\
\hline Simple phobia & $43(24)$ & $7(44)$ & $50(25)$ & \\
\hline GAD & $23(13)$ & $3(19)$ & $26(13)$ & \\
\hline OCD & $9(5)$ & - & $9(4)$ & \\
\hline PTSD & $2(I)$ & - & $2(1)$ & \\
\hline
\end{tabular}

BAI, Beck Anxiety Inventory; BDI, Beck Depression Inventory; BPD, borderline personality disorder; GAD, generalised anxiety disorder; HRSD, Hamilton Rating Scale for Depression; BHS, Beck Hopelessness Scale; OCD, obsessive-compulsive disorder; PSSS-R, Perceived Social Support Scale - Revised; PTSD, post-traumatic stress disorder; SOFAS, Social and Occupational Functioning Assessment Scale; SSI, Scale for Suicidal Ideation.

I. Fisher's exact test.

2. $\chi^{2}=7.764$, d.f. $=2$.

3. $F=9.427$, d.f. $=I$, ANOVA.

4. $F=10.367$, d.f. $=I$, ANOVA.

$5 . F=I l .228$, d.f. $=\mathrm{l}$, ANOVA.

6. $\chi^{2}=6.943$, d.f. $=\mathrm{I}$, Kruskal-Wallis test.

7. $F=3.665$, d.f. $=I$, ANOVA.

$8 . F=5.038$, d.f. $=$ I, ANOVA. 
Depression Inventory (Beck et al, 1961), Beck Anxiety Inventory (Beck et al, 1988), Beck Hopelessness Scale (Beck et al, 1974), Scale for Suicidal Ideation (Beck \& Kovacs, 1979), Social and Occupational Functioning Assessment Scale of DSM-IV (American Psychiatric Association, 1994: pp. 760-761), Interview for Recent Life Events (Paykel, 1983), Interview Measure of Social Relationships (Brugha et al, 1987) and the Perceived Social Support Scale-Revised (Blumenthal et al, 1987).

\section{Follow-up}

Of the 269 individuals with current major depressive disorder initially included in the study, 198 were still alive at the end of the study period, their depression had remained unipolar and they could be followed up (Melartin et al, 2004). At baseline, the majority $(154 / 198,78 \%)$ were receiving antidepressants at normal adult doses. The patients whose diagnosis switched to bipolar disorder during the follow-up $(13 / 269,5 \%)$ were analysed separately. The outcome of major depressive disorder and the comorbid disorders was investigated at 6 and 18 months by repeated SCAN 2.0 and SCID-II interviews, observer- and self-report scales and medical and psychiatric records. A detailed life chart was created, with time after baseline divided into three classes: state of full remission (none of the nine criteria symptoms for major depressive episode), partial remission (one to four symptoms); and major depressive episode (five or more symptoms). We used two different definitions for duration of the index episode: the uninterrupted duration of the episode in the state of major depression (time with full criteria) and time to the first onset of state of full remission that lasted at least 2 consecutive months (time to full remission) (Melartin et al, 2004).

Occurrence of a suicide attempt before the baseline interview and during the follow-up was based on both the interview and psychiatric records. By definition, a suicide attempt had to involve at least some degree of intent to die; self-harm with no suicidal intention was not included. Patient-months were calculated based on the life chart. Information about the deaths among all the 269 patients during the follow-up was obtained from the official records of Statistics Finland.

For the validity of the results it is essential to verify that there were no more suicidal patients among those who did not complete the study than among those followed up. This did not seem to be the case. Patients who could not be followed up did not differ from the patients who were followed up, in terms of suicide attempts before the index episode (18\% v. 14\%), suicide attempt during the index episode $(25 \% v .23 \%)$ or suicidal ideation $(38 \%$ v. $39 \%)$. However, they were somewhat younger, were more often living alone, had a higher score on the Eysenck Personality Inventory neuroticism scale (Eysenck \& Eysenck, 1964) and more often had comorbid dysthymia (Melartin et al, 2004).

\section{Statistical methods}

Logistic regression models were created, classifying suicide attempt during the follow-up as the dependent variable. The statistical methods included non-parametric and parametric univariate analyses (the $t$-test, $\chi^{2}$-test, Fisher's exact test, analysis of variance (ANOVA), the Mann-Whitney test and the Kruskal-Wallis test) and logistic regression models; the Statistical Package for the Social Sciences software, version 11.0 , was used.

\section{RESULTS}

During the 18-month follow-up, $16(8 \%)$ patients reported at least one suicide attempt but in total there were 41 discrete suicide attempts. Four occurred during a period of full remission, 12 during partial remission and 25 during a major depressive episode. Thus, the risk of a suicide attempt was 4/1201 patient-months during full remission, 12/1441 patient-months (relative risk 2.50) during partial remission and 25/ 995 patient-months (relative risk 7.54) during a major depressive episode $\left(\chi^{2}=24.3\right.$, d.f. $=2, P<0.001)$. Patients who switched to bipolar disorder and patients who died were not included. Of all the 269 patients in the cohort, eight patients $(3 \%)$ died during the 18 months after baseline, three $(1 \%)$ of them by suicide.
We found significant differences between those attempting suicide and those not attempting suicide (Table 1 ) in terms of: severity of index episode of depression; amount of suicidal ideation and anxiety; prevalence of personality disorder; prevalence of suicide attempts during the index episode; time to full remission and total time spent in a major depressive episode; and marital status (lack of partner). Patients with cluster B or borderline personality disorder had more attempts (Mann-Whitney test: $Z=-2.146, P=0.032$, and $Z=-2.165, P=0.030$, respectively).

In the logistic regression model predicting suicide attempts during the follow-up (Table 2), the predetermined covariates comprised gender, age, marital status, HRSD score, alcohol dependence or misuse, Beck Anxiety Inventory score, personality disorder (any), cluster B personality disorder, suicide attempt during the index episode and time spent in major depressive episodes. After removing the non-significant variables, three factors were strongly associated with suicide attempt: months spent in major depressive episodes $(\mathrm{OR}=1.13)$, suicide attempt during the index episode $(O R=5.62)$ and lack of partner $(\mathrm{OR}=5.10)$

Patients who switched to bipolar disorder $(13 / 269,5 \%)$ formed a particularly suicidal subgroup. They reported more suicidal ideation before the index episode $(9$ (69\%) v. 97 (38\%); Fisher's exact test, $P=0.039)$ and had more suicide attempts before the index episode (8 $(62 \%) v .56(22 \%)$; Fisher's exact test, $P=0.003)$ but this was nonsignificant during the follow-up (2 $(22 \%)$ v. $16(8 \%)$; Fisher's exact test, $P=0.17)$.

\section{DISCUSSION}

\section{Main findings}

During the 18-month prospective followup, $8 \%$ of patients with major depressive disorder attempted suicide. The risk of an attempt was almost eightfold during a

Table 2 Logistic regression model for suicide attempts during 18-month follow-up $(n=198)$

\begin{tabular}{lcccc}
\hline Variable & OR & $95 \% \mathrm{Cl}$ & Wald $\chi^{2}$ & $P$ \\
\hline Female & 1.39 & $0.36-5.28$ & 0.228 & 0.63 \\
Age (years) & 0.97 & $0.92-1.03$ & 1.136 & 0.29 \\
Total time in depression (months) & 1.13 & $1.03-1.26$ & 6.960 & 0.008 \\
Marital status (lack of parter) & 5.10 & $1.32-19.71$ & 5.589 & 0.01 \\
Suicide attempt at index episode & 5.62 & $1.69-18.61$ & 7.968 & 0.005 \\
\hline
\end{tabular}


major depressive episode compared with a period of full remission. Although many factors from various domains were associated with this risk, it was effectively predicted by three independent factors: lack of a partner, history of previous suicide attempts and time spent in major depressive episodes.

To our knowledge, the present study is the first prospective investigation to employ a life chart to place the suicide attempts, allowing us to identify important disparities in risk between periods with different levels of depressive symptoms. We interpret these robust findings as evidence for the causal role of depression per se in the aetiology of suicide attempts. Given the high level of comorbidity with anxiety, substance use and personality disorders in the patient population (Melartin et al, 2002), all factors that are related independently to suicidal behaviour, the finding is far from self-evident.

\section{Strengths, limitations and generalisability}

The present study has some major methodological strengths. It involved a relatively large $(n=269)$ cohort of both out- and inpatients with major depressive disorder, effectively representing all psychiatric patients with a new episode of major depressive disorder in a Finnish city. Based on an epidemiological survey, we have estimated (Rytsälä et al, 2001) that two-thirds of all individuals with major depressive disorder in the general population of the city of Vantaa seeking treatment from psychiatrists are treated in the Peijas Medical Care District. The patients were diagnosed carefully using structured interviews with excellent reliability $(\kappa=0.86)$ for the diagnosis of major depressive disorder, plus information on all comorbid Axis I and II disorders at baseline and later interviews. The total rate of losses to the study was low, because $87 \%$ of participants could be interviewed at least once after baseline. However, owing to deaths, diagnostic switch to bipolar disorder and patients who left the study after 6 months, those included in the present report represent $74 \%$ of the original 269 patients. These patients do not differ in terms of baseline suicidal behaviour from those who could not be included. The study took place during the era of current antidepressants (1997-1999) in a modern community psychiatric setting; at baseline, $78 \%$ of the patients received antidepressants at

\section{CLINICAL IMPLICATIONS}

- Psychiatric in- and out-patients with major depressive disorder have a high level of comorbidity with anxiety, substance use and personality disorder, all of which independently implicate elevated risk for suicide attempts. Nevertheless, risk for suicide attempt is about eightfold during a major depressive episode compared with full remission.

Risk for suicide attempts during follow-up is predicted independently and strongly by the time spent in major depressive episodes, suicide attempt during the index episode and lack of partner.

Reducing the time spent depressed is a credible preventive measure.

\section{LIMITATIONS}

- Total number of suicide attempts in the study was $4 \mathrm{I}$, made by only $16(8 \%)$ patients followed up. However, despite vulnerability to type II error, the main findings were highly significant statistically.

- Owing to deaths, diagnostic switch to bipolar disorder and dropping out, the patients interviewed represent $74 \%$ of the population at the baseline. Those who dropped out did not differ from those who remained, in terms of suicidal behaviour evaluated at baseline.

- The generalisability of the findings from psychiatric settings in Finland to psychiatric settings in other countries needs to be confirmed.

T. PETTERI SOKERO, MD, TARJA K. MELARTIN, MD, HEIKKI J. RYTSÄLÄ, MD, ULLA S. LESKELÄ, MA PAULA S. LESTELÄ-MIELONEN, MA, Department of Mental Health and Alcohol Research, National Public Health Institute, Helsinki and Department of Psychiatry at Peijas Hospital, Health Care District of Helsinki and Uusimaa, Vantaa, Finland; ERKKI T. ISOMETSÄ, MD, PhD, Department of Mental Health and Alcohol Research, National Public Health Institute, Helsinki, Finland

Correspondence: Erkki T. Isometsä, Head of Mood Disorders Research, Department of Mental Health and Alcohol Research, National Public Health Institute, Mannerheimintie 166, FIN- 00300 Helsinki, Finland. E-mail: erkki.isometsa@ktl.fi

(First received 24 March 2004, final revision 14 September 2004, accepted 30 September 2004)

adequate levels in the acute phase, in compliance with the American Psychiatric Association's Practice Guidelines. Methodological details are discussed more fully in earlier reports (Melartin et al, 2002; Sokero et al, 2003; Melartin et al, 2004). The most important limitation of the present study is that, despite a large cohort of patients, the number of suicide attempts was moderate and the number of patients attempting was small during the followup. Although the main findings are statistically robust, some degree of type II error may have occurred and some risk of spurious findings also exists. Finally, the density of psychiatrists per population in Finland is among the highest in Europe, and psychiatric settings treat about half of all individuals seeking treatment for depression from healthcare providers (Hämäläinen et al, 2004). Nevertheless, the characteristics of patients in the Vantaa Depression Study do not differ in terms of comorbidity and symptom severity from the few other studies that have reported them comprehensively (Zimmerman et al, 2000; Tedlow et al, 2002), supporting the generalisation of our findings to other settings.

\section{Predictors of suicide attempt}

Preceding the follow-up phase, $15 \%$ of the cohort had attempted suicide during the 
index episode and $24 \%$ before that (Sokero et al, 2003). The prevalence of those attempting suicide during the follow-up $(8 \%)$ in our study is similar to another report (Bronisch \& Hecht, 1992) but lower than in two others with populations apparently at higher risk (Duggan et al, 1991; Oquendo et al, 2002). Our univariate analysis findings are also in line with risk factor findings in our own baseline analysis (Sokero et al, 2003) and in the other studies. Marital status (Bronisch \& Hecht, 1992), major depressive disorder (Bronisch \& Hecht, 1992; Oquendo et al, 2002; Hansen et al, 2003; Sokero et al, 2003), anxiety (Fawcett et al, 1990; Sokero et al, 2003), personality disorder (Paykel \& Dienelt, 1971; Hansen et al, 2003; Sokero et al, 2003) and suicidal behaviour (Paykel \& Dienelt, 1971; Fawcett et al, 1990; Bronisch \& Hecht, 1992; Nordström et al, 1995; Oquendo et al, 2002; Sokero et al, 2003) were all associated with suicide attempts. In contrast to our cross-sectional findings (Sokero et al, 2003), substance use disorder, age, chronic physical illness and hopelessness did not, independently, predict suicide attempts. Finally, the small group of patients who switched to bipolar disorder during the follow-up appeared to be a particularly 'suicidal' subgroup. However, the number of cases was too small to evaluate risk factors for their suicidal behaviour.

\section{Clinical implications}

The clinical implications of our findings are clear. Suicide attempts among patients with major depressive disorder are strongly associated temporarily with the presence of depressive symptoms and robustly predicted by lack of a partner, previous suicide attempts and time spent depressed. Reducing the duration of a depressed state is likely to be an effective preventive measure for suicide attempts.

\section{REFERENCES}

American Psychiatric Association (1994) Diagnostic and Statistical Manual of Mental Disorders (4th edn) (DSM-IV). Washington, DC: APA.

Beck, A.T. \& Kovacs, M. (1979) Assessment of suicidal intention: a scale for suicidal ideation. Journal of Consulting and Clinical Psychology, 47, 343-352.

Beck, A. T., Ward, C. H., Mendelson, M., et al (1961) An inventory for measuring depression. Archives of General Psychiatry, 4, 56I-57I.

Beck, A. T., Weissman, A., Lester D., et al (1974) The measure of pessimism: the hopelessness scale. Journal of Consulting and Clinical Psychology, 42, 861-865.

Beck, A. T., Brown, G., Epstein, N., et al (1988) An inventory for measuring clinical anxiety: psychometric properties. Journal of Consulting and Clinical Psychology, 56, 893-897.

Blumenthal, J. A., Burg, M. M., Braefoot, J., et al (1987) Social support, type A behavior, and coronary artery disease. Psychosomatic Medicine, 49, 331-340.

Bronisch, T. \& Hecht, H. (1992) Prospective longterm follow-up of depressed patients with and without suicide attempts. European Archives of Psychiatry and Clinical Neuroscience, 242, 13-19.

Brugha, T. S., Sturt, E., MacCarthy, B., et al (1987) The Interview Measure of Social Relationships: the description and evaluation of a survey instrument for assessing personal social resources. Social Psychiatry, 22 $123-128$

Duggan, C. F., Sham, P., Lee, A. L., et al (1991) Can future suicidal behaviour in depressed patients be predicted? Journal of Affective Disorders, 21, III-1I8.

Eysenck, H. J. \& Eysenck, S. B. G. (1964) Manual of the Eysenck Personality Inventory. London: University of London Press.

Fawcett, J., Scheftner, W. A., Fogg, L., et al (1990) Time-related predictors of suicide in major affective disorder. American Journal of Psychiatry, 147, 1189-1194.

Hamilton, M. (1960) A rating scale for depression. Journal of Neurology, Neurosurgery and Psychiatry, 23, 56-62.

Hämäläinen, J., Isometsä, E., Laukkala, T., et a (2004) Use of health services for major depressive episode in Finland. Journal of Affective Disorders, 79, 105-112.

Hansen, P. E. B., Wang, A. G., Stage, K. B., et al (2003) The Danish University Antidepressant Group: comorbid personality disorder predicts suicide after major depression: a 10-year follow up. Acta Psychiatrica Scandinavica, 107, 436-440.

Isometsä, E.T., Henriksson, M. M., Aro, H. M., et al (1994) Suicide in major depression. American journal of Psychiatry, I5I, 530-536.
Malone, K. M., Haas, G. L., Sweeney, J. A., et al (1995) Major depression and the risk of attempted suicide. Journal of Affective Disorders, 34, 173-185.

Melartin, T. K., Rytsälä, H. J., Leskelä, U. S., et al (2002) Current comorbidity of DSM IV major depressive disorder in psychiatric care - Vantaa Depression Study. Journal of Clinical Psychiatry, 63, 126-135.

Melartin, T. K., Rytsälä, H. J., Leskelä, U. S., et a (2004) Severity and comorbidity predict episode duration and recurrence of DSM-IV major depressive disorder. Journal of Clinical Psychiatry, 65, 810-819.

Nordström, P., Åsberg, M., Åberg-Wistedt, A., et al (1995) Attempted suicide predicts suicide risk in mood disorders. Acta Psychiatrica Scandinavica, 92, 345-350.

Oquendo, M. A., Kamali, M., Ellis, S. P., et al (2002) Adequacy of antidepressant treatment after discharge and the occurrence of suicidal acts in major depression. American Journal of Psychiatry, 159, 1746-1751.

Osby, U., Brandt, L., Correia, N., et al (200I) Excess mortality in bipolar and unipolar disorder in Sweden. Archives of General Psychiatry, 58, 844-850.

Paykel, E. S. (1983) Methodological aspects of life event research. Journal of Psychosomatic Research, 27, 34I-352.

Paykel, E. S. \& Dienelt, M. N. (197I) Suicide attempts following acute depression. Journal of Nervous and Mental Disease, 153, 234-243.

Rytsälä, H. J., Melartin, T. K., Leskelä, U., et al (200I) A record-based investigation of 803 patients treated for depression in psychiatric care. Journal of Clinical Psychiatry, 62, 70I-706.

Sokero, T. P., Melartin, T. K., Rytsälä, H. J. et a (2003) Suicidal ideation and attempts among psychiatric patients with major depressive disorder. Journal of Clinical Psychiatry, 64, 1094-1100.

Spitzer, R. L., Williams, J. B.W., Gibbon, M., et a (1987) Structured Clinical Interview for DSM-III-R Personality Disorder (SCID-II). New York: Biometrics Research Department, New York State Psychiatric Institute.

Tedlow, J., Smith, M., Neault, N., et al (2002) Melancholia and Axis II comorbidity. Comprehensive Psychiatry, 43, 33I-335.

Wing, J. K., Babor, T., Brugha, T., et al (1990) SCAN Schedules for Clinical Assessment in Neuropsychiatry. Archives of General Psychiatry, 47, 589-593.

Zimmerman, M., McDermut, W. \& Mattia, J. I. (2000) Frequency of anxiety disorders in psychiatric outpatients with major depressive disorder. American Journal of Psychiatry, I57, 1337-1340. 